BMJ Open Diabetes Research $\&$ Care

\title{
Preventing diabetes after pregnancy with gestational diabetes in a Cree community: an inductive thematic analysis
}

\author{
Romina Pace,${ }^{1,2}$ Orenda Loon, ${ }^{3}$ Deborah Chan, ${ }^{2}$ Helene Porada, ${ }^{3}$ \\ Catherine Godin, ${ }^{3}$ Jonathan Linton, ${ }^{3}$ Paul Linton, ${ }^{3}$ Jill Torrie, ${ }^{3}$ \\ Kaberi Dasgupta (D) ${ }^{1,2}$
}

To cite: Pace R, Loon 0 , Chan D, et al. Preventing diabetes after pregnancy with gestational diabetes in a Cree community: an inductive thematic

analysis. BMJ Open Diab Res Care 2020;8:e001286. doi:10.1136/

bmjdrc-2020-001286

- Additional material is published online only. To view please visit the journal online (http://dx.doi.org/10.1136/ bmjdrc-2020-001286).

Received 14 February 2020 Revised 19 March 2020 Accepted 23 April 2020

Check for updates

(C) Author(s) (or their employer(s)) 2020. Re-use permitted under CC BY-NC. No commercial re-use. See rights and permissions. Published by BMJ.

'Department of Medicine, McGill University, Montreal, Quebec, Canada

${ }^{2}$ Centre for Outcomes Research and Evaluation, Research Institute of the McGill University Health Centre, Montreal, Quebec, Canada

${ }^{3}$ Public Health Department, Cree Board of Health and Social Services of James Bay, Chisasibi, Quebec, Canada

Correspondence to Dr Kaberi Dasgupta; kaberi.dasgupta@mcgill.ca

\section{ABSTRACT}

Introduction Historical and political factors underpin the disproportional burden of type 2 diabetes mellitus (T2DM) and gestational diabetes mellitus (GDM) in women, a harbinger of future T2DM, in Indigenous populations. There is a need for T2DM prevention strategies driven by the voices of Indigenous women. In this study, we aimed to understand the perspectives of Cree women with prior GDM living in northern Quebec, where over a quarter of pregnancies are complicated by GDM.

Research design and methods A local healthcare worker invited women with GDM in the prior 5 years to participate in semistructured interviews. A Cree-origin research partner and a researcher jointly conducted interviews in-person or by teleconference. Open-ended questions addressed GDM experience, maintaining a healthy lifestyle, and needs/preferences pertinent to designing a T2DM prevention program aimed at women affected by GDM. We adopted an inductive thematic analysis framework to categorize experiences and opinions.

Results Among the 13 mothers interviewed, some success with health behavior changes during pregnancy was reported but there were difficulties postpartum resulting from time constraints, costs of healthy foods, discomfort at the gym related to not being perceived as athletic, and safety concerns. They acknowledged the existence of programs addressing T2DM prevention in their community but did not participate. They endorsed preferences for group sessions, with family collaboration and childcare, that addressed healthy cooking and physical activity and incorporated traditional elements.

Conclusion Cree mothers with a history of GDM highlighted several barriers to diabetes prevention. We are working to address these barriers through the creation of a Cree-facilitator-led community-based intervention.

\section{BACKGROUND}

Gestational diabetes mellitus (GDM) resolves after delivery but is a well-established type 2 diabetes mellitus (T2DM) risk indicator. ${ }^{12}$ GDM predicts diabetes risk not only in the mother but also in their partners and children. ${ }^{134}$ A high proportion of Indigenous women develop T2DM following a GDM

\section{Significance of this study}

What is already known about this subject?

- Indigenous populations are confronting spiraling rates of type 2 diabetes mellitus (T2DM) and gestational diabetes mellitus (GDM) in women. Proactive T2DM prevention strategies tailored to the needs and wants of Indigenous women are needed to curb this epidemic. There is a research gap in this area.

What are the new findings?

- The study is the first to specifically examine perspectives of Indigenous Canadian women on barriers and facilitators to healthy eating and physical activity following a GDM pregnancy.

- Time pressures as a barrier and family collaboration and childcare as facilitators were consistent with perspectives of non-indigenous women reported in prior studies.

- Safety concerns (as related, for example, to dogs in the community), healthy food costs, and gym avoidance because of stigma from 'more athletic' individuals were reported as distinct barriers.

- An emphasis on traditional foods would be appreciated in a diabetes prevention program.

How might these results change the focus of research or clinical practice?

- These results signal considerations in designing community-based diabetes prevention interventions that may be relevant to other Indigenous communities.

pregnancy; in a Canadian study, $76.0 \%$ of Indigenous women developed T2DM over a follow-up period of up to 30 years compared with $56.2 \%$ of non-Indigenous women. ${ }^{5}$ Historical and political factors underpin the disproportional burden of diabetes in Indigenous populations. ${ }^{6}$ The Truth and Reconciliation Committee underscored the importance of closing health gaps (19 and 53iv) between Indigenous and non-Indigenous Canadians. ${ }^{7}$ 
In the Cree communities of Eeyou Istchee (EI) in Quebec, a quarter of pregnant women develop GDM. ${ }^{8}$ Historically, when the Cree were engaged in the mercantile fur trade, as producers of fur and wage employees at the posts, their diet was hunted, fished, and gathered from the land, and, up to the 1970 s, access to market foods was limited. ${ }^{9}$ From the 1960s and 1970s, the public sector economy began to define the post settlements into the year-round communities we know today. Now, sugarsweetened beverages, snack foods, fast foods, and baked goods represent as much as $40 \%-50 \%$ of the energy intake of community members' diets. ${ }^{9}$ Food prices average $30 \%$ more than in other parts of Quebec. ${ }^{10}$ Recent initiatives have aimed at supporting the component of the Cree economy grounded in bush food harvesting, processing, and consumption. Additionally, healthcare delivery in the region is complicated by the high turnover of healthcare professionals. ${ }^{11}$ Further, most Cree mothers are unable to deliver locally and need to travel outside their community to centers up that can be greater than 8 hours away by road.

There is an urgent need to develop and implement effective and acceptable programs with Indigenous peoples to prevent T2DM. A GDM pregnancy offers a 'window of opportunity' to provide effective T2DM prevention by promoting healthy eating and increased physical activity; an individualized eating and physical activity behavioral change program led to a greater than $50 \%$ reduction in T2DM incidence among women with pre-diabetes, including those with a GDM history in a general population-based American study. ${ }^{12}$ There are limited studies among Indigenous women with GDM and very few to date have been shown to be effective. ${ }^{13-15}$ The Society of Obstetricians and Gynecologists of Canada ${ }^{16}$ and Diabetes Canada ${ }^{17}$ call for collaboration with Indigenous communities to innovate culturally safe community-led health promotion projects. We conducted interviews to understand what type of T2DM prevention program would be welcomed by young mothers in EI and their families following a GDM pregnancy.

\section{METHODS}

Setting

This descriptive qualitative study ${ }^{18}$ was conducted in an EI community in Quebec. Recruitment occurred in collaboration with the Awash Miyupimaatisiiun clinic that follows women during and after pregnancy in the community.

\section{Participants and sampling strategy}

Using purposive sampling, mothers with GDM in the previous 5 years (2013-2019) were identified by an Awash Miyupimaatisiiun clinic team member. Eligible mothers were then invited by clinic staff to be contacted by the research team (April 2018 to June 2019). The research team's Cree partner confirmed no current diagnosis of T2DM by phone and scheduled an interview. Mothers were also invited to bring their partners to the interviews.
Written and verbal informed consent was obtained from all participants.

\section{Data collection}

Using a semistructured guide (online supplementary file 1), 30-60 min interviews were conducted jointly by (1) a university researcher ( $\mathrm{RP}$ or $\mathrm{KD}$ or $\mathrm{DC}$ ) in-person or by phone and (2) a local research partner (JL or OL) in-person at the Cree Board of Health and Social Services James Bay (CBHSSJB) public health offices in the community. Interviews were conducted in English and/or Cree. Cree questions and responses were translated into English during the interview by the local Cree research partner. Participant information was deidentified and digital audio recordings were transcribed verbatim.

Participants were asked to share (1) their GDM experience, (2) perspectives on maintaining a healthy lifestyle, and (3) needs and preferences in a T2DM prevention program. We also explored their opinions on intervention elements tested in a Montreal-based program called MoMMii (eg, cooking sessions, physical activity programs, on-site childcare, participation of partners/ family members). ${ }^{19} 20$

\section{Data analysis}

Transcripts were analysed through an inductive thematic analysis framework. ${ }^{21}$ Transcripts were manually coded independently by two assessors (RP and $\mathrm{KD}$ ) to determine emerging themes and subthemes; each assessor compared text segments across the transcripts, seeking similar or repeated ideas expressed by participants, and coded them accordingly. Following their independent assessments, the assessors met to compare, contrast, and refine existing codes until they reached consensus on main themes and the grouping of subthemes within the main themes.

\section{RESULTS}

\section{Participants}

Thirteen women were interviewed, two with male partners. Six women were pregnant at the time of interview. The mean age of the mothers was 30.5 years (SD: 7.5). They averaged three pregnancies each, and six had had more than one GDM pregnancy. The majority $(10 / 13)$ required insulin for GDM management with the remainder treated with diet and physical activity counselling alone. Most $(11 / 13)$ reported a family history of T2DM.

\section{Main themes}

The six main themes (table 1) expressed by the women regarding their experience of GDM were (1) worry, anxiety, and guilt, (2) understanding of GDM and its implications, (3) sources of support, (4) awareness of necessary health behavioral changes, (5) challenges to optimizing health behaviors, and (6) needs and preferences for a T2DM prevention program. 
Table 1 Summary of main themes and associated subthemes among sample if Eeyou Iscthee mothers with a recent gestation diabetes mellitus (GDM) pregnancy

\begin{tabular}{|c|c|c|}
\hline Main theme & Subtheme & Sample quotes \\
\hline $\begin{array}{l}\text { 1. Worry, anxiety, and } \\
\text { guilt }\end{array}$ & $\begin{array}{l}1.1 \text { Insulin injections } \\
1.2 \text { Complications with baby } \\
\text { 1.3 Recurrent GDM and } \\
\text { diabetes } \\
\text { 1.4 Guilt } \\
\text { 1.5 Anticipation of GDM } \\
\text { diagnosis } \\
\text { 1.6 Disbelief of GDM } \\
\text { diagnosis }\end{array}$ & $\begin{array}{l}\text { "I kind of getting scared because, like, poking yourself every day, and my mum-it's really } \\
\text { known in my family too, to have diabetes. So my mum kind of scared me a little bit too, } \\
\text { telling me that if you don't take care of yourself or you don't even try, it's just going to stick } \\
\text { with you." } \\
\text { "I cried. I didn't-like, I was worried, like, everything I eat, what's going to happen to my } \\
\text { baby" } \\
\text { "I experienced being diabetic for sure. But yeah, I don't know, I'm - it makes me worried that } \\
\text { I might just have it again, even without being pregnant." } \\
\text { "I felt a lot of guilt. You know, like, you know, it was my fault, and then I just, like, was very, } \\
\text { very meticulous about what I was eating and-and that kind of brought me into a depression } \\
\text { as well." } \\
\text { "I was devastated the first time I found out because I thought, you know, like, I-I'm healthy. } \\
\text { You know, I'm-I'm active. I eat healthy. You know, like, I don't-I don't get it. How do I } \\
\text { have GDM when I see all these other pregnant women, and they don't have it, but I do? You } \\
\text { know, like, what's going on?" }\end{array}$ \\
\hline $\begin{array}{l}\text { 2. Understanding } \\
\text { of GDM and its } \\
\text { implications }\end{array}$ & $\begin{array}{l}2.1 \text { Awareness of future } \\
\text { diabetes risk } \\
2.2 \text { Knowledge of GDM } \\
2.3 \text { Need for ongoing } \\
\text { education on diabetes } \\
\text { prevention }\end{array}$ & $\begin{array}{l}\text { "Yeah, it goes away shortly after birth, but then you have a higher risk of-so it's better to } \\
\text { keep the good habits that you had." } \\
\text { "It was a lot to take in, but I got through it as they were telling me it was going to be okay. } \\
\text { They were really good." } \\
\text { "It was more like, "Oh, your blood sugar's a little high. You have to watch. Here's a } \\
\text { glucometer." }\end{array}$ \\
\hline 3. Sources of support & $\begin{array}{l}\text { 3.1 Clinic staff } \\
\text { 3.2 Partner } \\
\text { 3.3 Family } \\
\text { 3.4 Peers with GDM }\end{array}$ & $\begin{array}{l}\text { "I met with the nutritionist, and I had my nurse's cell phone number. So, like, when I had } \\
\text { weird numbers or something, I was able to call and ask them." } \\
\text { "He (partner) really helped me a lot. Like, we would go for walks and tell me it's okay, just } \\
\text { how do you say it-watch what you're eating." } \\
\text { "If I had any questions, I'd go to my family, or if they couldn't answer, I would just go to the } \\
\text { clinic and they would have the answers for me." } \\
\text { "I think for women with GDM, I think a support group. Because everybody has different ways } \\
\text { of dealing with things, and sometimes people don't know what questions to ask. And then } \\
\text { when they hear somebody else ask the question, they're, like, oh, okay, yeah." }\end{array}$ \\
\hline $\begin{array}{l}\text { 4. Awareness of } \\
\text { necessary health } \\
\text { behavioral changes }\end{array}$ & $\begin{array}{l}\text { 4.1 Diet changes } \\
\text { 4.2 Regular physical activity }\end{array}$ & $\begin{array}{l}\text { "Picking better protein choices, because we live in an area where we can have choices, and } \\
\text { that's great. So, like, goose, bear meat, anything, anything traditional, I try and stick to that." } \\
\text { "Like having vegetables daily. Like, half of the plate is supposed to be full of vegetables and } \\
\text { a quarter of it should be, like, meat or chicken and a quarter of carbs, because we need still } \\
\text { carbs. So yeah, that's eating fruits and vegetables, snacks and - healthy snacks." } \\
\text { "Being more active, walking more to work (...) Doing more than I'm doing now. It doesn't } \\
\text { mean I have to run a marathon or do a fitness challenge. It just means doing more." }\end{array}$ \\
\hline $\begin{array}{l}\text { 5. Health behavioral } \\
\text { change challenging }\end{array}$ & $\begin{array}{l}\text { 5.1 Time constraints } \\
\text { 5.2 Lack of childcare } \\
\text { 5.3 Safety concerns } \\
\text { 5.4 Cost } \\
\text { 5.5 Worry of being judged }\end{array}$ & $\begin{array}{l}\text { "When you work nine to five and you have two kids, you're just, like, totally drained out." } \\
\text { "I hear a lot of parents say - like, let's say if I asked them, let's go for a walk and they would } \\
\text { say, oh, I don't have a babysitter." } \\
\text { "A lot of people(just don't)walk on the highway, and then when you walk on the skidoo trail, } \\
\text { there's skidoos going." } \\
\text { "Like, healthy food, it could be more expensive." } \\
\text { "At the gym to have a bigger gym workout and not to pay. Because I know other } \\
\text { communities (...) don't pay the gym fee. But here we pay, like, } \$ 300 \text { or something." } \\
\text { "I've went in there (local gym) once. But there's too many people there. They're all, like, } \\
\text { strong, built people and then here you come and you're, like, this chunky short person. I'm } \\
\text { just, like, no, I can't." }\end{array}$ \\
\hline $\begin{array}{l}\text { 6. Needs and } \\
\text { preferences for a } \\
\text { T2DM prevention } \\
\text { program }\end{array}$ & $\begin{array}{l}\text { 6.1 Partner involvement } \\
\text { 6.2 Childcare } \\
\text { 6.3 Group activities } \\
\text { 6.4 Scheduled activities } \\
\text { 6.5 Education on increasing } \\
\text { healthy behaviors } \\
\text { 6.6 Traditional elements }\end{array}$ & $\begin{array}{l}\text { "We have to do things together in order to have a healthy life and a healthy baby." } \\
\text { "(Onsite childcare) would be really helpful because Mom and Dad would be able to focus, } \\
\text { and a lot of times around here, it's just really hard to find a sitter." } \\
\text { "Well, to do it alone, it would be nice. But I think that being with other people, you get to } \\
\text { learn other people's - like, how they do it and it might help you do it at home better or if you } \\
\text { help them out. Like, everyone gets to talk." } \\
\text { "A lot of activities, like constantly, like, every day having to go walk or something." } \\
\text { "I would love to learn, like, exercises too, exercises I can do at home or while l'm with my } \\
\text { kids. It would be something fun to do with our kids." } \\
\text { "Traditional food too because a lot of-like, there's healthy ways to cook traditional food and } \\
\text { there's unhealthy ways to cook traditional food." }\end{array}$ \\
\hline
\end{tabular}

GDM, gestational diabetes mellitus; T2DM, type 2 diabetes mellitus.

\section{Worry, anxiety, and guilt}

Some women expressed anxiety regarding the possible need for insulin injections (subtheme (ST) 1.1) (I didn't like it when I first found out that I'm diabetic ... Because of the insulin.). Their greatest fears were about the risks to their babies (ST 1.2) (when you're diabetic I guess, GDM, there can be a lot of complications with the baby too. So I was kind of getting scared.).

Mothers worried about future implications of their diagnosis. Some indicated they considered avoiding future 
pregnancies (ST 1.3) because they feared a recurrence (That's one of the reasons why I don't want to have another one (child).). Having friends and family with T2DM, for several mothers the diagnosis of GDM raised concerns about their own future risks (I think about it (T2DM) maybe a few times a week, yeah. I think about it more often than I would if I didn't have it (GDM) or if I didn't have people that had it (diabetes) in my family.).

There was a sense of guilt about the diagnosis, which in some cases was anticipated (ST 1.4, ST 1.5) (I had a feeling that I was already and that it was likely to happen because I was overweight.) and in other cases, the diagnosis came as a shock (ST 1.6) (I was just wanting to know how could — how is this, you know, how could I-how did this happen?).

\section{Understanding of GDM and its implications}

Mothers were aware that GDM is a risk indicator for T2DM (ST 2.1) (I'm curious if I'm going to-if I will have diabetes afterwards.). Some felt that they were well informed about the diagnosis (It was a lot to take in, but I got through it as they were telling me it was going to be okay.), while others indicated that they were given little information on GDM and its management (They just asked me to check my sugars after I ate, like, when I woke up and everything.) (ST 2.2).

Knowing they were at risk for T2DM in the future, mothers expressed a need for more education on diabetes prevention for themselves and other community members with GDM (ST 2.3) (...all women hear is, well, you have diabetes, or you have GDM. And then it just stops there [...] So I think maybe just reinforcing, re-teaching of course, but finding a way that maybe can help them understand that it's-it'll either come back or you're more at risk for it or yes, it's chronic, so you need to manage it.).

\section{Sources of support}

Some women indicated good levels of support from the local clinic team (ST 3.1), while others were less satisfied with the nutritional support they received (I did meet with the nutritionist early on in the pregnancy, but like I said, there was no, like, follow-up.). Support from partners and family members was essential for many mothers in making the lifestyle changes needed to treat their GDM (ST 3.2 and ST 3.3) (There were times where I was just, like, I'm just going to eat this, you know, I don't really - I'm craving for this. I want this. (...) it was hard, but I had my parents, my husband telling me, like, "No, you can do it."). The mothers interviewed expressed a desire for a peer support group to share their experiences (ST 3.4) (To be able to discuss with other people that are going through the same thing. Because I had GDM, and my aunt who was pregnant at the same time didn't. And so, like, I couldn't really relate to her.).

\section{Awareness of necessary health behavioral changes}

Mothers recognized that healthier eating and being more active were ways of reducing their risk of T2DM (ST 4.1 and ST 4.2). Examples included cooking food at home themselves (I like knowing what goes in my food or in my kid's food.) and eating fewer carbohydrates (Eating less carbs because I was-we were, like-we enjoyed spaghetti, that type of stuff. But I changed my noodles to whole wheat noodles, but eating less of $i t$.), more fruits and vegetables, smaller portions, and more traditional foods (I always think that our traditional diet probably is the best one for us, which would be more protein.). Mothers indicated that their current levels of physical activity should be increased (Doing more than I'm doing now. It doesn't mean I have to run a marathon or do a fitness challenge. It just means doing more.). Walking, snowshoeing, exercising at home, and engaging in activities with their children were identified as ways of incorporating regular physical activity into their lives.

\section{Challenges to optimizing health behaviors}

Physical activity and healthy cooking programs are available in the community, but the majority of the mothers interviewed did not participate and did not know many people who did (They do have programs, but they're not utilized by the community. They -I think they had a walking program at one point. We have a beautiful new trail that's, you know, could be really, really nice to use that more often. They do healthy cooking, but I don't know how much people go to it. You, like, you -I know it's there, but I don't go.). Time constraints (ST 5.1), lack of childcare (ST 5.2), and safety (It's mostly I would say, like, the dogs, and the skidoos.) (ST 5.3) were identified as barriers to participation. Women acknowledged the local gym as a physical activity resource, but none were members. Some felt uncomfortable at the gym (ST 5.5) (I've went in there [local gym] once. But there's too many people there. They're all, like, strong, built people and then here you come and you're, like, this chunky short person. I'm just, like, no, I can't.). Cost was also a barrier, both for gym membership and purchasing healthy food (ST 5.4).

\section{Needs and preferences pertinent to T2DM prevention program}

Cree mothers expressed that health behavior changes would be easier if the whole family adopted the changes and if childcare were available to allow them more time to be physically active (ST 6.1 and ST 6.2). Although there were existing programs in the community where children were permitted, the children were a distraction, particularly during cooking lessons (like here the cooking class, we cook with the kids. But it's kind of hard because, like, they're very limited with certain things. It's kind of hard, and they want to do it ...). They highlighted that group activities would be beneficial to share experiences and partner participation would also be appreciated (ST 6.1 and ST 6.3).

Having a schedule of regular activities was thought to be important (ST 6.4). Classes on healthy cooking ( $I$ think if they showed more of a healthier way to cook it, then it would be better.), grocery tours (To be familiar with the ingredients on grocery shopping would be very helpful too, how to read the ingredients.), walking clubs, more instructor-led physical activity sessions, and home exercise program were endorsed by mothers as activities that would be beneficial to mothers with GDM (ST 6.5). Access to recipes, health applications on their cellular phones, pedometers to track physical activity, and information 
available in a centralized location were identified as aids they would also appreciate as part of a T2DM prevention program (ST 6.5). Mothers were interested in both traditional and non-traditional recipes (ST 6.6). Incorporating traditional forms of Indigenous physical activity was also discussed (ST 6.6). Some women indicated that they previously participated in such activities and were concerned these traditions were being overlooked ( $a$ lot of youth out there doesn't really recognize traditional ways. So that's one way to promote the ways of learning and showing them a healthy lifestyle.).

\section{INTERPRETATION}

The Cree mothers whom we interviewed experienced anxiety, worry, and guilt about their children's health and their own after being diagnosed with GDM. They were knowledgeable about necessary behavioral changes but encountered difficulties in applying this knowledge both during and after pregnancy. Many expressed the need for support from family, health professionals, and peers to achieve health changes. Interviewees supported the concept of group sessions addressing healthy cooking and physical activity, with on-site childcare. They believed that such a program should incorporate traditional foods and activities.

In the late 1990s, a clinical trial in EI examined the effect of one-on-one nutritional counseling on weight gain in pregnancy and development of GDM. ${ }^{15}$ Weight gain and GDM incidence were similar in both intervention and control arms. Based on discussion with Cree mothers, the Special Working Group of the Cree Regional Child and Family Services Committee wrote in a letter to the editor that participants would have preferred a group-based approach as well as interactions with local Cree facilitators. ${ }^{22}$ This is consistent with the type of program structure endorsed by the women and couples whom we interviewed.

Three previous qualitative studies have examined diabetes during pregnancy among Indigenous women in Canada. In a Manitoba-based study, Neufeld and colleagues reported that mothers with GDM expressed fear, anxiety, frustration, and anger regarding their ability to make dietary changes. This led to a sense of failure and ineffective diabetes management. ${ }^{23}$ These emotions were interconnected with social and economic stressors. The women also reported that they had little knowledge and awareness of GDM and had poor relationships with healthcare providers. In contrast, the women whom we interviewed indicated fewer struggles and more support. The women in the Neufeld's study received perinatal care in an urban setting, whereas in our study most of their care was delivered within the community and thus was perhaps better tailored to meet the realities of Indigenous pregnant women. ${ }^{23}$

Similar to our study, in a study among pregnant Algonquin First Nations women with GDM, family and peer support were primary motivators to maintain healthy behaviors, ${ }^{24}$ and in a study among urban dwelling First Nations mothers, the importance of supportive relationships was also highlighted. ${ }^{25}$ In this latter study, the importance of cultural support was also underscored. Maintaining lifestyle changes after pregnancy was not examined in these studies but was the focus of ours. A recent systematic review, which included 21 studies on women's perspectives on lifestyle changes after GDM, the authors concluded that women require resources, time, energy, childcare, information, and support to encourage physical activity and nutritional changes. ${ }^{26}$ These needs were echoed by the Cree women we interviewed. However, in addition, the women in our study emphasized the importance of incorporating traditional foods and activities.

This is the first study to examine the opinions of Indigenous women on maintaining healthy diet and physical activity after a GDM pregnancy and their thoughts on the elements required for a successful health promotion program in their community for women with GDM and their families. There are some limitations to our study. Almost half of the women interviewed were pregnant at the time of their interview, and this may have limited their ability to distinguish between their needs and wants during and after pregnancy. Additionally, we could not capture the perspectives of women who did not come to the Awash clinic for care; women who do not present for prenatal care may have mistrust of the healthcare system ${ }^{27}$ and are a more vulnerable population. Our results may also be applicable largely to in-community (previously termed 'reserves') Cree women and may not be generalizable to city-dwelling Indigenous women. Thus, to some extent the external validity of our results is limited as Indigenous communities have unique cultures, geographic, political, and socioeconomic factors. However, these results may nonetheless signal considerations relevant to other Indigenous communities in designing community-based T2DM prevention programs.

Based on our interviews, assessment of community resources, and discussions with local partners, an intervention tailored to the EI context will be implemented with the support of the CBHSSJB public health department and Awash Miyupimaatisiiun clinic. A key component of the intervention will be a health behavioral change facilitator who will provide the support sought by the respondents in the current study. A local Cree origin facilitator, who is also a mother with a past history of GDM, has been identified to lead the program. She will recruit participants and foster the development of a peer community. She will maintain and distribute a calendar of diabetes prevention-related activities, rally study participants to attend, and arrange childcare and transportation. We trust that this initiative built on Cree views, needs, and local capacity will be a key step forward in addressing diabetes prevention in EI by improving the health status of mothers, fathers, and children. 
Contributors All authors have contributed significantly and in keeping with the latest guidelines of the International Committee of Medical Journal Editors. RP, HP, CG, PL, JT and KD collaborated on the study design. OL and JL contacted potential interviewees and coordinated organization of interviews. RP, OL, DC, JL and KD conducted interviews and participated in data collection. RP and KD conducted the data analysis and drafted the manuscript. All authors have read and approved the submission of the manuscript.

Funding The study was funded by Lawson Foundation.

Competing interests None declared.

Patient consent for publication Not required.

Ethics approval This study was approved by McGill University's Faculty of Medicine Institutional Review Board (2018-3302) and the Cree Board of Health and Social Services James Bay (CBHSSJB).

Provenance and peer review Not commissioned; externally peer reviewed.

Data availability statement The data that support the findings of this study are available on request from the corresponding author $\mathrm{KD}$. The data are not publicly available due to restrictions to protect the privacy of research participants.

Open access This is an open access article distributed in accordance with the Creative Commons Attribution Non Commercial (CC BY-NC 4.0) license, which permits others to distribute, remix, adapt, build upon this work non-commercially, and license their derivative works on different terms, provided the original work is properly cited, appropriate credit is given, any changes made indicated, and the use is non-commercial. See: http://creativecommons.org/licenses/by-nc/4.0/.

ORCID iD

Kaberi Dasgupta http://orcid.org/0000-0002-2447-3553

\section{REFERENCES}

1 Pace R, Brazeau A-S, Meltzer S, et al. Conjoint associations of gestational diabetes and hypertension with diabetes, hypertension, and cardiovascular disease in parents: a retrospective cohort study. Am J Epidemiol 2017;186:1115-24.

2 Song C, Lyu Y, Li C, et al. Long-Term risk of diabetes in women at varying durations after gestational diabetes: a systematic review and meta-analysis with more than 2 million women. Obes Rev 2018;19:421-9.

3 Dasgupta K, Ross N, Meltzer S, et al. Gestational diabetes mellitus in mothers as a diabetes predictor in fathers: a retrospective cohort analysis. Diabetes Care 2015;38:e130-1.

4 Blotsky AL, Rahme E, Dahhou M, et al. Gestational diabetes associated with incident diabetes in childhood and youth: a retrospective cohort study. CMAJ 2019;191:E410-7.

5 Shen GX, Shafer LA, Martens PJ, et al. Does First Nations ancestry modify the association between gestational diabetes and subsequent diabetes: a historical prospective cohort study among women in Manitoba, Canada. Diabet Med 2016;33:1245-52.

6 Harris SB, Tompkins JW, TeHiwi B. Call to action: a new path for improving diabetes care for Indigenous peoples, a global review. Diabetes Res Clin Pract 2017;123:120-33.

7 Truth, Canada RCo. Truth and reconciliation Commission of Canada: calls to action: truth and reconciliation Commission of Canada, 2015.
8 Dannenbaum D, Torrie JE, Lejeune P. Report from the Cree diabetes information system (CDIS) 2017 update, 2018.

9 Nieboer E, Dewailly E, Johnson-Down L. Nituuchischaayihtitaau Aschii Multi-community Environment-and-Health study in Eeyou Istchee 2005-2009: final technical report. 16. Chisasibi QC Cree Board of Health and Social Services of James Bay, 2013.

10 Vinet-Lanouette C, Godin C, Menard V, et al. Access to a nutritious food basket in Eeyou Istchee (2016 update, 2017.

11 Minore B, Boone M, Katt M, et al. The effects of nursing turnover on continuity of care in isolated first nation communities. Can J Nurs Res 2005;37:86-100.

12 Ratner RE, Christophi CA, Metzger BE, et al. Prevention of diabetes in women with a history of gestational diabetes: effects of metformin and lifestyle interventions. J Clin Endocrinol Metab 2008;93:4774-9.

13 Dyck RF, Sheppard MS, Cassidy H, et al. Preventing NIDDM among Aboriginal people: is exercise the answer? description of a pilot project using exercise to prevent gestational diabetes. Int $J$ Circumpolar Health 1998;57 Suppl 1:375-8.

14 Klomp H, Dyck R. Description and evaluation of a prenatal exercise program for urban Aboriginal women. Can J Diabetes 2003;27.

15 Gray-Donald K, Robinson E, Collier A, et al. Intervening to reduce weight gain in pregnancy and gestational diabetes mellitus in Cree communities: an evaluation. CMAJ 2000;163:1247-51.

16 Wilson D, Ronde Sdela, Brascoupé S, et al. Health professionals working with First Nations, Inuit, and Métis consensus guideline. Journal of Obstetrics and Gynaecology Canada 2013;35:550-3.

17 Diabetes Canada Clinical Practice Guidelines Expert Committee, Crowshoe L, Dannenbaum D, et al. Type 2 diabetes and Indigenous peoples. Can J Diabetes 2018;42 Suppl 1:S296-306.

18 Sandelowski M. Whatever happened to qualitative description? Res Nurs Health 2000;23:334-40.

19 Brazeau A-S, Leong A, Meltzer SJ, et al. Group-based activities with on-site childcare and online support improve glucose tolerance in women within 5 years of gestational diabetes pregnancy. Cardiovasc Diabetol 2014:13:104

20 Brazeau A-S, Meltzer SJ, Pace R, et al. Health behaviour changes in partners of women with recent gestational diabetes: a phase IIA trial. BMC Public Health 2018;18:575.

21 Braun V, Clarke V. Using thematic analysis in psychology. Qual Res Psychol 2006;3:77-101.

22 Planning research for greater community involvement and long-term benefit. Special Working Group of the Cree regional child and family services Committee. CMAJ 2000;163:1273-4.

23 Neufeld HT. Food perceptions and concerns of Aboriginal women coping with gestational diabetes in Winnipeg, Manitoba. J Nutr Educ Behav 2011;43:482-91.

24 Gaudreau S, Michaud C. Cultural factors related to the maintenance of health behaviours in Algonquin women with a history of gestational diabetes. Chronic Dis Inj Can 2012;32:140-8.

25 Oster RT, Mayan MJ, Toth EL. Diabetes in pregnancy among First Nations women. Qual Health Res 2014;24:1469-80.

26 Dennison RA, Ward RJ, Griffin SJ, et al. Women's views on lifestyle changes to reduce the risk of developing type 2 diabetes after gestational diabetes: a systematic review, qualitative synthesis and recommendations for practice. Diabet Med 2019;36:702-17.

27 Jacklin KM, Henderson RI, Green ME, et al. Health care experiences of Indigenous people living with type 2 diabetes in Canada. CMAJ 2017;189:E106-12. 